\title{
Cardiovascular
}

\section{A SAMPLING STUDY OF BLOOD PRESSURE LEVELS IN WHITE AND NEGRO RESIDENTS OF NASSAU, BAHAMAS}

\author{
Benjamin C. Johnson, M.D., Dr.P.H., AND \\ Richard D. Remington, Ph.D.
}

ANN ARBOr, Mich.
From the University of Michigan School of Public Health

(Received for publication June 1, 1960)

$\mathrm{M}$ ANY factors have been tentatively identified as correlates of blood pressure. These include age, sex, race, body build or obesity, dietary components, particularly sodium, and genetic susceptibility. While there is general agreement that each of these factors plays some role, the exact quantitative nature of this role is a subject of controversy.

Some of the disagreement present in the literature on blood pressure is no doubt due to the differing composition of the groups that have been studied and to preoccupation with study of a single factor, all other factors being neglected or ignored. For a discussion of some of the factors influencing blood pressure, see Pickering. ${ }^{7}$

The population of the Bahama Islands offers a unique opportunity for simultaneous study of several of the important factors related to blood pressure. Residents of these islands are primarily Negro, although about 20 per cent of the population is Caucasian. This permits the simultaneous study of the factors of race, age, and sex. Another interesting feature of the Bahamas is the known high sodium content of the water supply. The importance of salt intake in the pathogenesis of hypertension is controversial, but no good data are available in regard to population differences in salt intake compared to distributions of blood pressure.

There have been many studies of the distribution of blood pressure in human populations. In general, these studies have been concerned with special groups of people, such as insurance policy holders, industrial workers, and clinic outpatients and inpatients. Each of these groups might possibly differ in blood pressure distribution, thus making it a potentially poor representative of a large general

This study was partially supported by a grant from the United States Public Health Service, National Institutes of Health (H-3577).

'I'he basic data in this paper were abstracted from a dissertation submitted in partial fulfllment of requirements for the degree of Doctor of Public Health at the University of Michigan. 
population. On the other hand, there have been several studies of large populations which do not suffer from this particular difficulty. Some investigators have studied communities, whereas others have studied scientifically designed samples of a community. Some of these efforts, however, have suffered from the failure to get observations from many of the people designated for study, again inviting statistical criticism.

It would be extremcly difficult to sample adequately the entire population of the Bahama Islands. The population is scattered among a great number of islands, over a large geographic area. The Island of New Providence is the cultural and geographic center of the island group, however, and contains the only relatively large city in the islands, the city of Nassau. Thus, Nassau was selected as the site of the study hecause it is centrally located in the island group, contains a concentration of population, and probably represents a melting pot of the people of the entire colony.

\section{METHODS}

Selection of the Sample.-The sample of residents of the city of Nassau selected for this study is technically known as a stratified one-stage cluster sample. The basic sampling unit consisted of a segment of approximately 40 dwelling units, usually consisting of a city block, or part of a city block. In a preliminary canvass of the population of the city of Nassau, these sampling units were stratified, or divided into groups on the basis of geographic area, racial composition of the residents, and a rough index of socioeconomic status. Ten Negro strata, containing 17 or 18 sampling units each, were so identified. An additional stratum containing a racially mixed population and consisting of 16 sampling units was defined. A twelfth stratum, consisting mainly of white residents and containing 12 sampling units, completed the stratification of the population. Two sampling units were selected at random from each of the Negro strata and from the mixed stratum. Because of the relatively small number of white residents, and because of the need to secure a racial comparison in the study, 4 sampling units were selected at random from the white stratum.

The considerations leading to the choice of this size for the sample include the physical and financial resources available to the study, and the desire to analyze the data separately for the various age, sex, and race groups.

The selected sample was studied over a 6 -week period, and data were collected on 92 per cent of the individuals falling into the sample. This yielded 1,250 Negro women, 990 Negro men, 362 white women, and 325 white men. Some families of obviously mixed racial stock were studied but, unfortunately, were too few in number for analysis.

Interview and Examination Procedure.-This study was designed to permit examinations to be carried out in the subject's home. Home examinations promised more complete coverage of families. Furthermore, a casual blood pressure taken at home probably provides a reasonably accurate measure of the blood pressure a person "lives with" when not subjected to stress, although it is perhaps affected to some degree by the presence of a strange person in the home. Examinations were, of necessity, performed when the individual subject could be found 
at home. This frequently involved several callbacks before an entire family could be examined. For this reason, variation in blood pressure duc to time of day, elapsed time since last meal, fatigue, etc., could not be compensated for by standardization. Most of the people were seen between 2 and 9 P.M., although some were seen in the morning.

Examinations were done in almost equal numbers by one physician (senior author) and 4 senior medical students from the University of Michigan. The interview itself was standardized so that information was gathered in a systematic manner. The medical data were collected in the following order: (1) arm girth measurement, (2) first casual blood pressure reading, (3) first pulse rate, (4) height measurement, (5) weight measurement, (6) second blood pressure, (7) second pulse rate.

Blood pressure readings were taken from the left arm, with the subject in the sitting position. In the blood pressure determinations, both fourth phase diastolic (muffling) and fifth phase diastolic (disappearance) were recorded. Pulse rates, timed for 15 seconds, were taken immediately after blood pressure readings. Height and weight measurements were routinely recorded after the first blood pressure and pulse. The blood pressure cuff was left on the arm, since this sped up the examination procedure, and did not materially affect the recorded weight. Simple bathroom scales, portable in a brief case, were used for recording weight. All the five scales used agreed to within three pounds when checked for accuracy. Height was measured to the nearest half inch, with a firm cloth tape, after the height was marked on a wall, the subject standing without shoes. Arm girth was measured to the nearest quarter inch, at the point of maximum circumference of the upper left arm. This firm cloth tape was felt to be comparable in accuracy to a flexible metal tape.

The total elapsed time between blood pressure measurements was one to two minutes. Sphygmomanometers were of the aneroid type, compared daily for accuracy with a mercury manometer as a standard.

In the course of the actual examination procedure, persons were told either that their blood pressure was normal, borderline high, or high. The criterion used for the most part was diastolic pressure. All subjects with diastolic blood pressure over $110 \mathrm{~mm}$. $\mathrm{Hg}$ were referred to their physician or to the Colonial Medical Service. Diastolic pressures between 100 and $110 \mathrm{~mm}$. Hg were called borderline and these persons were advised to consult their physician at a later date. Others were called "normal." Some exceptions to these criteria were made in young people, older persons with extremely wide pulse pressures, and others with suggestive symptoms. All these were also referred to their physicians.

Pretesting and Standardization.-After thorough familiarization with the methods and procedures of examination, all examiners engaged in a field test in order to insure uniformity of information collected, and of examination routine. An area of the city not included in the sample was used in the pretest. The examiners worked in pairs during the pretest, observing each other's technique, until it was felt that all were comparable.

Prior to the collection of any of the actual data presented here, an additional standardization experiment was undertaken for the purpose of estimating inter- 
Table I. Means of Blood Pressure Readings in Age, Sex, and Race Groups, With Standard Error of Mean-Nassau, 1958

\begin{tabular}{|c|c|c|c|c|c|c|c|}
\hline \multicolumn{4}{|c|}{ MALES } & \multicolumn{4}{|c|}{ FEMALES } \\
\hline $\mathbf{A G E}$ & MEAN & $\begin{array}{c}\text { STANDARD } \\
\text { ERROR }\end{array}$ & $\begin{array}{l}\text { NO, IN } \\
\text { GROUP }\end{array}$ & $\mathrm{AGE}$ & MEAN & $\begin{array}{c}\text { STANDARD } \\
\text { ERROR }\end{array}$ & $\begin{array}{l}\text { NO. IN } \\
\text { GROUP }\end{array}$ \\
\hline \multicolumn{8}{|c|}{ Systolic Blood Pressure, White Race.- } \\
\hline $\begin{array}{c}6-9 \\
10-14 \\
15-19 \\
20-24 \\
25-29 \\
30-34 \\
35-39 \\
40-44 \\
45-49 \\
50-54 \\
55-59 \\
60+\end{array}$ & $\begin{array}{l}105.90 \\
114.92 \\
128.74 \\
126.75 \\
130.17 \\
124.97 \\
124.91 \\
135.47 \\
128.01 \\
138.73 \\
140.56 \\
144.08\end{array}$ & $\begin{array}{l}2.57 \\
2.12 \\
1.19 \\
3.33 \\
2.62 \\
2.55 \\
4.75 \\
2.41 \\
3.52 \\
3.32 \\
8.44 \\
6.91\end{array}$ & $\begin{array}{l}45 \\
28 \\
33 \\
34 \\
30 \\
38 \\
22 \\
22 \\
20 \\
14 \\
11 \\
28\end{array}$ & $\begin{array}{c}6-9 \\
10-14 \\
15-19 \\
20-24 \\
25-29 \\
30-34 \\
35-39 \\
40-44 \\
45-49 \\
50-54 \\
55-59 \\
60+\end{array}$ & $\begin{array}{l}104.71 \\
116.90 \\
120.18 \\
122.74 \\
117.91 \\
122.69 \\
120.53 \\
145.15 \\
145.04 \\
145.01 \\
160.70 \\
156.88\end{array}$ & $\begin{array}{l}1.69 \\
1.26 \\
1.87 \\
4.97 \\
3.68 \\
2.86 \\
4.74 \\
7.38 \\
2.49 \\
3.90 \\
6.33 \\
3.51\end{array}$ & $\begin{array}{l}47 \\
36 \\
31 \\
43 \\
39 \\
33 \\
27 \\
25 \\
20 \\
15 \\
16 \\
30\end{array}$ \\
\hline \multicolumn{8}{|c|}{ Systolic Blood Pressure, Negro Race.- } \\
\hline $\begin{array}{c}6-9 \\
10-14 \\
15-19 \\
20-24 \\
25-29 \\
30-34 \\
35-39 \\
40-44 \\
45-49 \\
50-54 \\
55-59 \\
60+\end{array}$ & $\begin{array}{l}101.53 \\
109.37 \\
125.11 \\
128.03 \\
132.97 \\
135.89 \\
142.85 \\
142.09 \\
145.30 \\
155.85 \\
144.68 \\
168.78\end{array}$ & $\begin{array}{l}1.03 \\
0.62 \\
1.02 \\
1.24 \\
1.83 \\
2.72 \\
5.09 \\
3.17 \\
2.85 \\
4.92 \\
9.34 \\
8.80\end{array}$ & $\begin{array}{r}154 \\
143 \\
139 \\
123 \\
98 \\
58 \\
55 \\
67 \\
67 \\
37 \\
16 \\
33\end{array}$ & $\begin{array}{c}6-9 \\
10-14 \\
15-19 \\
20-24 \\
25-29 \\
30-34 \\
35-39 \\
40-44 \\
45-49 \\
50-54 \\
55-59 \\
60+\end{array}$ & $\begin{array}{l}102.56 \\
111.53 \\
118.81 \\
119.65 \\
126.79 \\
132.41 \\
140.26 \\
149.61 \\
152.88 \\
155.99 \\
182.42 \\
176.41\end{array}$ & $\begin{array}{l}0.51 \\
1.03 \\
1.23 \\
1.46 \\
2.01 \\
1.48 \\
2.16 \\
4.82 \\
2.04 \\
5.43 \\
5.93 \\
3.53\end{array}$ & $\begin{array}{r}166 \\
139 \\
153 \\
170 \\
128 \\
86 \\
109 \\
87 \\
75 \\
46 \\
30 \\
61\end{array}$ \\
\hline \multicolumn{8}{|c|}{ Diastolic Blood Pressure, Fifth Phase, White Race. - } \\
\hline $\begin{array}{c}6-9 \\
10-14 \\
15-19 \\
20-24 \\
25-29 \\
30-34 \\
35-39 \\
40-44 \\
45-49 \\
50-54 \\
55-59 \\
60+\end{array}$ & $\begin{array}{l}61.31 \\
62.60 \\
71.18 \\
72.65 \\
74.06 \\
77.30 \\
79.39 \\
84.95 \\
79.15 \\
87.75 \\
83.47 \\
79.42\end{array}$ & $\begin{array}{l}2.53 \\
2.20 \\
2.18 \\
1.78 \\
4.06 \\
0.92 \\
1.01 \\
1.75 \\
1.32 \\
2.16 \\
2.25 \\
2.91\end{array}$ & $\begin{array}{l}45 \\
28 \\
33 \\
34 \\
30 \\
38 \\
22 \\
22 \\
20 \\
14 \\
11 \\
28\end{array}$ & $\begin{array}{c}6-9 \\
10-14 \\
15-19 \\
20-24 \\
25-29 \\
30-34 \\
35-39 \\
40-44 \\
45-49 \\
50-54 \\
55-59 \\
60+\end{array}$ & $\begin{array}{l}66.90 \\
66.96 \\
67.38 \\
73.30 \\
76.55 \\
78.94 \\
77.86 \\
86.38 \\
85.42 \\
86.69 \\
86.25 \\
81.58\end{array}$ & $\begin{array}{l}2.38 \\
1.31 \\
0.91 \\
1.88 \\
0.90 \\
2.97 \\
0.92 \\
3.69 \\
2.65 \\
1.83 \\
2.88 \\
1.16\end{array}$ & $\begin{array}{l}47 \\
36 \\
31 \\
43 \\
39 \\
33 \\
27 \\
25 \\
20 \\
15 \\
16 \\
30\end{array}$ \\
\hline \multicolumn{8}{|c|}{ Diastolic Blood Pressure, Fifth Phase, Negro Race. - } \\
\hline $\begin{array}{c}6-9 \\
10-14 \\
15-19 \\
20-24 \\
25-29 \\
30-34 \\
35-39 \\
40-44 \\
45-49 \\
50-54 \\
55-59 \\
60+\end{array}$ & $\begin{array}{l}63.79 \\
66.29 \\
73.56 \\
78.69 \\
82.93 \\
87.75 \\
91.58 \\
91.42 \\
94.41 \\
93.15 \\
86.97 \\
90.33\end{array}$ & $\begin{array}{l}0.90 \\
0.55 \\
1.27 \\
1.25 \\
1.38 \\
2.11 \\
2.52 \\
1.72 \\
2.21 \\
1.93 \\
3.99 \\
4.45\end{array}$ & $\begin{array}{r}154 \\
143 \\
139 \\
123 \\
98 \\
58 \\
55 \\
67 \\
67 \\
37 \\
16 \\
33\end{array}$ & $\begin{array}{c}6-9 \\
10-14 \\
15-19 \\
20-21 \\
25-29 \\
30-34 \\
35-39 \\
40-44 \\
45-49 \\
50-54 \\
55-59 \\
60+\end{array}$ & $\begin{array}{l}64.71 \\
67.18 \\
71.06 \\
73.81 \\
80.40 \\
84.68 \\
88.18 \\
90.84 \\
92.14 \\
91.56 \\
98.15 \\
89.74\end{array}$ & $\begin{array}{l}0.76 \\
1.13 \\
1.19 \\
1.13 \\
1.25 \\
1.11 \\
1.58 \\
2.62 \\
0.92 \\
2.52 \\
1.41 \\
1.66\end{array}$ & $\begin{array}{r}166 \\
139 \\
153 \\
170 \\
128 \\
86 \\
109 \\
87 \\
75 \\
46 \\
30 \\
61\end{array}$ \\
\hline
\end{tabular}


observer variability in the blood pressure and pulse determinations. Five different subjects were observed by the five field examiners. The examinations were arranged so that the effects of three potential sources of variation could be measured. These were: (1) variation between the subjects, (2) variation between the examiners, and (3) variation due to the order in which the subjects were examined. The examination of each subject by each observer included three successive blood pressure and pulse determinations. Both fourth and fifth phase diastolic pressures were recorded, and pulses were taken with fifteen second readings. Briefly, the results of this standardization experiment were as follows: (1) Variation between subjects was great. (2) Variation due to order of observation was slight or minimally significant statistically. (3) Variation due to observers was not significant for any of the blood pressure variables.

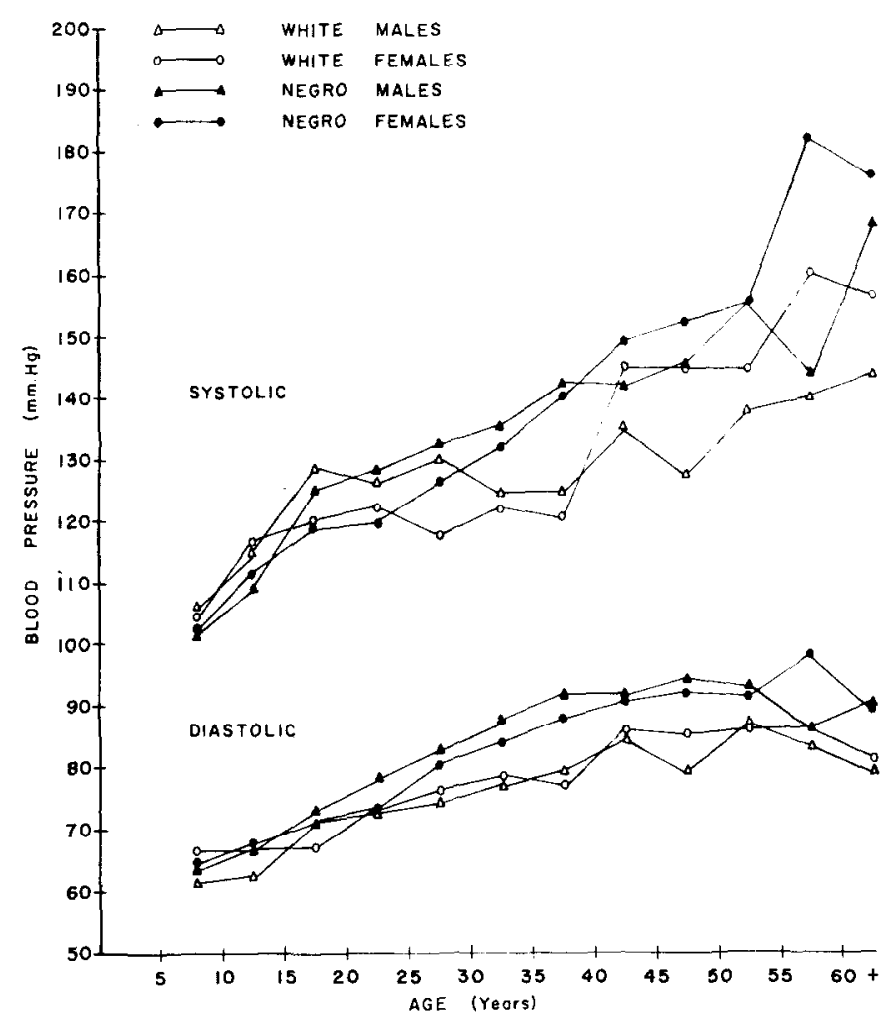

Fig. 1.-The mean systolic and diastolic blood pressure by age, race, and sex-Nassau, 1958.

\section{RESULTS}

Table I presents the basic results of the study. The first two sections present the systolic blood pressure for both the white and Negro races, by sex and age. The last two parts present similar results for diastolic (fifth phase). The fourth phase diastolic pressure was recorded routinely but is not presented in this report. Findings were essentially similar to the fifth phase data. 
In Fig. I the means of systolic and diastolic (fifth phase) blood pressure are plotted by age, sex, and race. The most striking impression from this figure is the apparent difference in the pattern of progression with age. The nature of this difference is of interest.
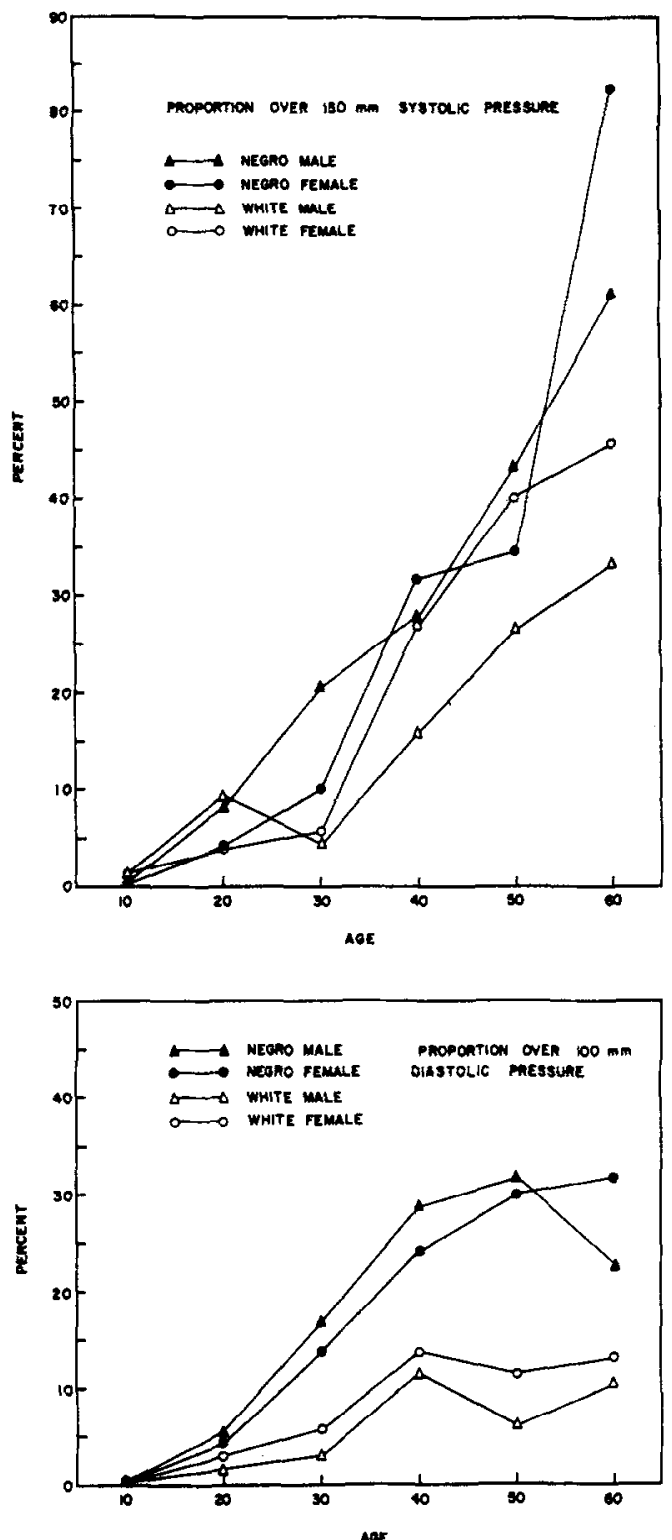

Fig. 2.- The proportion of persons within the age, sex, race group with blood pressure over arbitrary break points within the Negro and white races-Nassau, 1958.

The mean diastolic pressures gradually increase from early childhood to age 55, when they begin to fall slightly. From age 20, the Negro means continue upward fairly steadily, while the means for the white persons remain more nearly 
constant. It is also interesting that, after adolescence, there is a very slight but consistently higher mean diastolic pressure for Negro males as compared with Negro females until about age 55 . This consistent relationship is not demonstrable in the white race.

In the graph of mean systolic pressures, the increase in the mean by age in the Negro race is seen to be quite regular, proceeding upward in an almost linear fashion. Systolic pressure for the white race seems to rise quite rapidly from childhood to early adulthood (slightly exceeding the Negro means). From this point, however, the white persons show a plateau effect, or a flattening of the progression of pressure with age. At about age 40 (as was seen in the diastolic means) a rather sudden change is seen toward increasing pressures, most marked in the female.

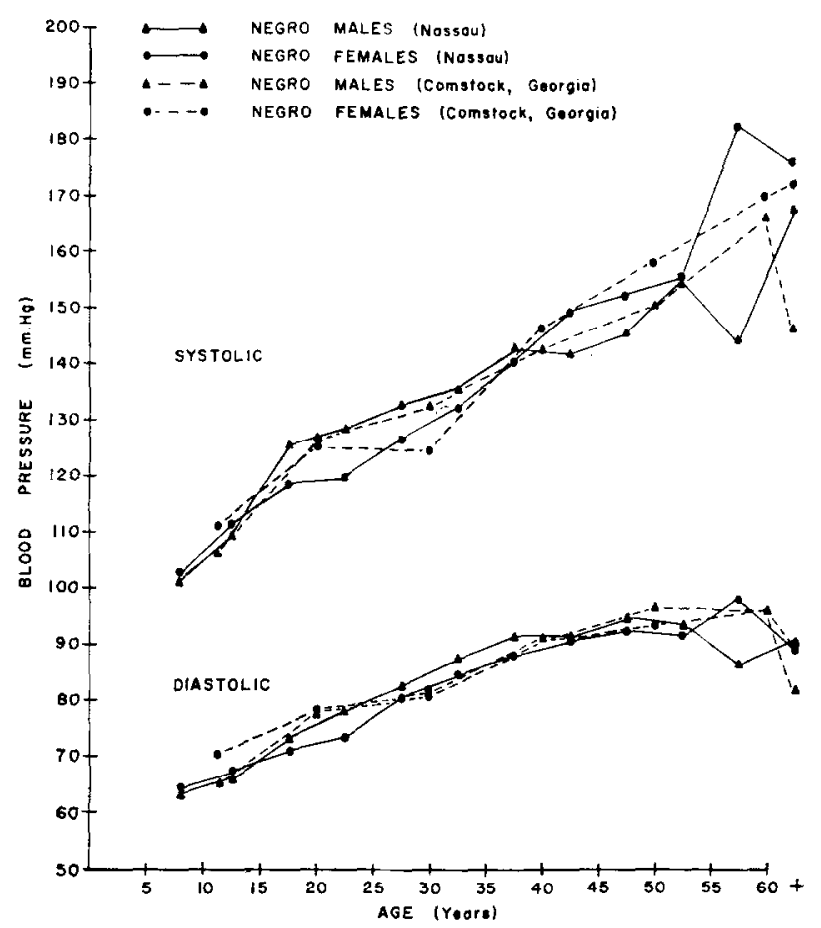

Fig. 3.-The mean systolic and diastolic blood pressure by age in the Negro race-Nassau, 1958, and Georgia.

In regard to the differences by sex, it is seen that there is very little difference between the sexes of either race in childhood. After adult levels are reached (about age 17), the male of both races has consistently higher systolic pressure than the female during the reproductive period. This is somewhat more marked in the white race. In both races this relationship is reversed at almost the same time in life, about age 40. The "crossover" of the lines at the end of the reproductive period suggests that women enjoy a degree of immunity to hypertension during these years which is lost at about the age of menopause. The menopause per se has not previously been shown to have a hypertensive effect, at least no sudden 
change not attributable to increase in age. Sex differences in regard to blood pressure have not been adequately explained. The "crossover" of the curves at the age of the menarche and at the menopause, however, suggests a relationship between these physiologic changes and the basic mechanism of blood pressure control.

The pattern in diastolic pressure means does not show this clear-cut sex difference. In fact, the Negro male tends to maintain a very slight but consistently higher mean than the female from adolescence to about age 55 .

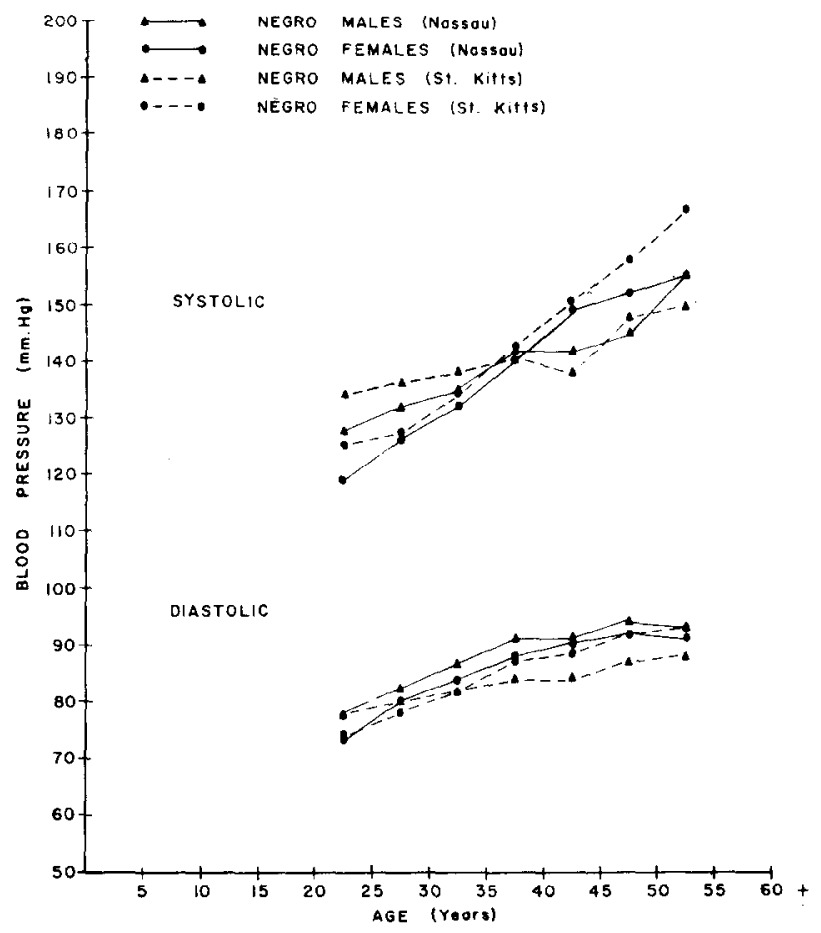

Fig. 4.-The mean systolic and diastolic blood pressure by sex and age in the Negro race-Nassau, 1958, and St. Kitts, Leeward Islands. (Schneckloth and Corcoran. ${ }^{8}$ )

Fig. 2 describes the racial and sex differences from the point of view of proportions of age-sex-race groups which have blood pressures over specific cut points. In this figure, the cut points are $150 \mathrm{~mm}$. systolic pressure and $100 \mathrm{~mm}$. diastolic pressure. The racial difference is again clearly demonstrable. This graph is generally similar to Fig. 1, although points of crossover in regard to sex are obscured.

Comparison With Other Studies.-External comparisons were made with results in similar racial groups in similar population studies. Comparisons with the data from Comstock, ${ }^{2}$ Miall, ${ }^{5}$ and Boe ${ }^{1}$ lead one to believe that white persons in Nassau are not very different from these other populations in regard to blood pressure. The Negro race in Nassau was compared specifically with studies done among Negroes in Georgia ${ }^{2}$ and in St. Kitts (Leeward Islands). ${ }^{8}$ Figs. 3 and 4 
show the remarkable similarity of Negroes in Nassau to Negroes in these other areas. Racial origin (West Africa) is assumed to be similar. The most notable difference affecting these populations is that while Bahamian Negroes have a high salt content in their water supply, and presumably also in food intake, the Negroes in St. Kitts have a relatively low salt intake in both food and water. ${ }^{8}$

Nassau water is gathered from numerous wells which vary in salinity. To obtain an impression of average salinity, a total of 76 samples were taken during

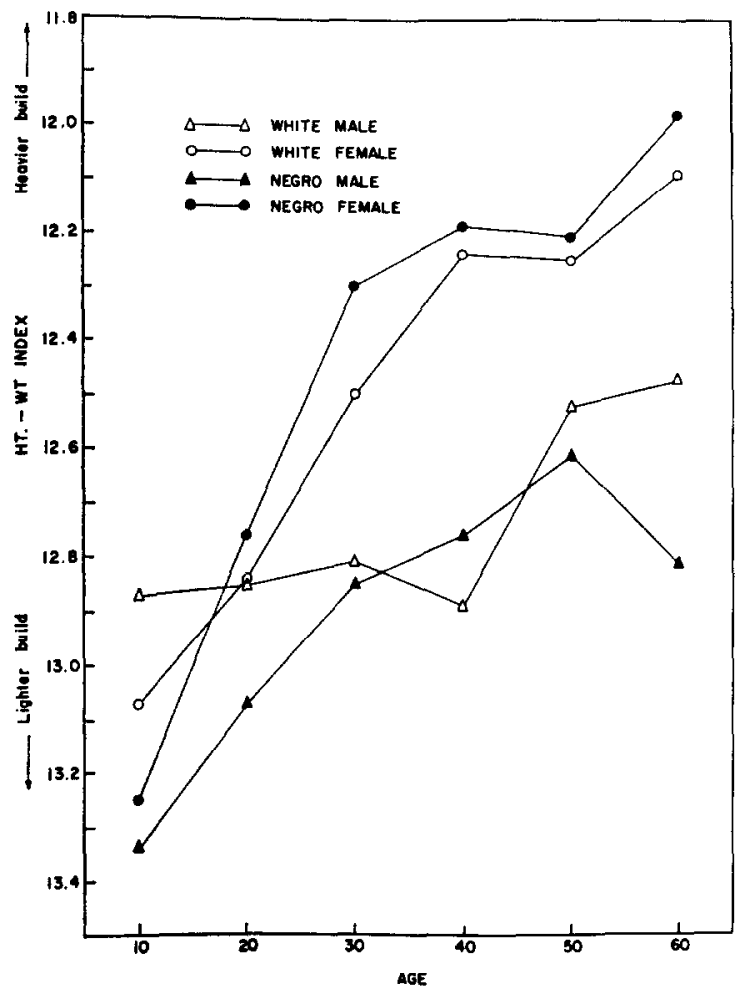

Fig. 5.-The mean of height-weight index by age, Negro and white races-Nassau, 1958.

the study period. Water was sampled in every area from which blood pressure measurements were taken. Essentially the same water was used by both races. Average salinity was $117 \mathrm{mg}$. per liter and ranged from 54 to $200 \mathrm{mg}$. per liter. Most eastern U. S. water supplies seem to contain less than $15 \mathrm{mg}$. per liter and occasionally as much as $50 \mathrm{mg}$. per liter. In some areas of the western U.S. salinity figures may be higher than those found in Nassau. ${ }^{4}$

Body Build.--In the present study data were obtained on height, weight, and arm girth. Height and weight were not studied separately, but rather by means of a ponderal index (height/cube root of weight). Such an estimate is not a direct indication of obesity, but represents leanness as opposed to heaviness. Negroes, on the average, appeared to be more heavily muscled than white persons. The present data show a tendency to an increase of pressure (both systolic and diastolic) with increasing heaviness. Although a low index usually represented 
Table II. Relationship of Height-Weight Index (Height/Cube Root of Weight) to Blood Pressure Within Age-Sex Groups-White Race, Nassau, 1958

\begin{tabular}{|c|c|c|c|c|c|c|c|}
\hline \multicolumn{4}{|c|}{ MALES } & \multicolumn{4}{|c|}{ FEMALES（NONPREGNANT） } \\
\hline $\begin{array}{l}\text { HT.-WT. } \\
\text { INDEX }\end{array}$ & $\begin{array}{l}\text { SYSTOLIC } \\
\text { MEAN }\end{array}$ & $\begin{array}{l}\text { DIASTOLIC } \\
\text { MEAN }\end{array}$ & $\begin{array}{l}\text { NO. IN } \\
\text { GROUP }\end{array}$ & $\begin{array}{l}\text { HT.-WT. } \\
\text { INDEX }\end{array}$ & $\begin{array}{c}\text { SYSTOLIC } \\
\text { MEAN }\end{array}$ & $\begin{array}{l}\text { DIASTOLIC } \\
\text { MEAN }\end{array}$ & $\begin{array}{l}\text { NO. IN } \\
\text { GROUP }\end{array}$ \\
\hline \multicolumn{8}{|c|}{ Age 6-9 } \\
\hline 10 & - & - & - & 10 & - & - & - \\
\hline 11 & 104.3 & 62.8 & 18 & 11 & 107.1 & 70.6 & 22 \\
\hline 12 & 103.2 & 59.4 & 22 & 12 & 102.5 & 61.6 & 16 \\
\hline 13 & - & 二 & - & 13 & - & - & - \\
\hline 14 & - & 一 & - & 14 & - & 一 & - \\
\hline 10 & 132.8 & 80.0 & 5 & 10 & - & - & - \\
\hline 11 & 118.8 & 64.4 & 50 & 11 & 120.1 & 66.2 & 22 \\
\hline 12 & 129.1 & 69.3 & 7 & 12 & 115.1 & 67.0 & 48 \\
\hline 13 & - & - & 一 & 13 & 104.0 & 68.0 & 1 \\
\hline 14 & - & - & - & 14 & - & - & - \\
\hline & & & \multicolumn{2}{|c|}{ Age 20-29 } & & & \\
\hline 10 & 140.0 & 79.3 & 6 & 10 & 134.1 & 83.2 & 12 \\
\hline 11 & 123.4 & 73.7 & 47 & 11 & 118.5 & 72.8 & 69 \\
\hline 12 & 114.7 & 65.3 & 3 & 12 & 108.0 & 76.0 & 1 \\
\hline 13 & - & 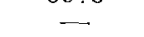 & - & 13 & - & - & - \\
\hline 14 & - & - & & 14 & - & - & - \\
\hline & & & \multicolumn{2}{|c|}{ Age $30-39$} & & & \\
\hline 10 & - & - & - & 10 & 123.2 & 81.4 & 13 \\
\hline 11 & 128.3 & 80.2 & 41 & 11 & 119.1 & 74.7 & 45 \\
\hline 12 & 117.4 & 70.5 & 24 & 12 & 114.7 & 80.7 & 3 \\
\hline 13 & - & - & - & 13 & - & - & - \\
\hline 14 & 一 & - & & 14 & - & - & - \\
\hline & & & \multicolumn{2}{|c|}{ Age $40-49$} & & & \\
\hline 10 & - & - & & 10 & 151.1 & 92.6 & 19 \\
\hline 11 & 132.6 & 81.9 & 27 & 11 & 140.6 & 84.5 & 24 \\
\hline 12 & 133.5 & 82.8 & 17 & 12 & 157.0 & 78.0 & 2 \\
\hline 13 & - & - & - & 13 & - & - & - \\
\hline 14 & - & - & \multirow{2}{*}{\multicolumn{2}{|c|}{ Age $50-59^{17}$}} & - & - & - \\
\hline & & & & & & & \\
\hline $\begin{array}{l}10 \\
11\end{array}$ & 126.1 & 82.2 & 7 & 10 & 157.6 & 91.2 & 15 \\
\hline 11 & 141.3 & 84.3 & 19 & 11 & 146.8 & 86.3 & 28 \\
\hline 12 & - & - & - & 12 & - & - & - \\
\hline 13 & - & -- & -- & 13 & 一 & 一 & - \\
\hline 14 & - & - & - & Age $60+{ }^{14}$ & - & - & - \\
\hline 10 & 一 & - & - & 10 & 169.2 & 84.8 & 13 \\
\hline 11 & 137.9 & 77.9 & 16 & 11 & 160.2 & 81.6 & 29 \\
\hline 12 & 155.3 & 83.4 & 12 & 12 & 148.0 & 68.7 & 3 \\
\hline 13 & - & - & $\ldots$ & 13 & - & - & - \\
\hline 14 & - & - & - & 14 & 一 & - & - \\
\hline
\end{tabular}

obesity, a heavily muscled person of the same height could have the same index as an obese person. The magnitude of the differences between means for different indices ranged from 1 to $78 \mathrm{~mm}$. systolic pressure and from 1 to $54 \mathrm{~mm}$. diastolic pressure, without discernible change in this regard with age, except in the young. Because of the size of the groups the study of Negroes yields more valid figures (Tables II and III). However, the pattern of progression of these mean indices by age (increasing heaviness) does not correspond to the pattern of mean blood pressure increase with age (Fig. 5). It appears that women of both races and men 
Table III. Relationship of Height-Weight Index (Height/Cube Root of Weight) to Blood Pressure Within Age-Sex Groups-Negro Race, Nassau, 1958

\begin{tabular}{|c|c|c|c|c|c|c|c|}
\hline \multicolumn{4}{|c|}{ MALES } & \multicolumn{4}{|c|}{ FEMALES (NONPREGNANT) } \\
\hline $\begin{array}{l}\text { HT.-WT. } \\
\text { INDEX }\end{array}$ & $\begin{array}{l}\text { SYSTOLIC } \\
\text { MEAN }\end{array}$ & $\begin{array}{l}\text { DIASTOLIC } \\
\text { MEAN }\end{array}$ & $\begin{array}{l}\text { NO. IN } \\
\text { GROUP }\end{array}$ & $\begin{array}{l}\text { HT.-WT. } \\
\text { INDEX }\end{array}$ & $\begin{array}{l}\text { SYSTOLIC } \\
\text { MEAN }\end{array}$ & $\begin{array}{l}\text { DIASTOLIC } \\
\text { MEAN }\end{array}$ & $\begin{array}{l}\text { NO. IN } \\
\text { GROUP }\end{array}$ \\
\hline \multicolumn{8}{|c|}{ Age 6-9 } \\
\hline 10 & 100.0 & 60.0 & 1 & 10 & - & - & -- \\
\hline 11 & - & $\overline{-}$ & - & 11 & 99.5 & 42.0 & 2 \\
\hline 12 & 101.2 & 64.5 & 40 & 12 & 102.4 & 65.7 & 30 \\
\hline 13 & 100.8 & 62.9 & 78 & 13 & 102.4 & 64.3 & 92 \\
\hline 14 & 95.0 & 63.0 & 2 & 14 & 101.3 & 64.2 & 9 \\
\hline \multicolumn{8}{|c|}{$\operatorname{Age} 10-19$} \\
\hline 11 & 135.5 & 73.0 & 2 & 11 & 126.2 & $\begin{array}{r}120.0 \\
68.4\end{array}$ & ${ }_{9}^{1}$ \\
\hline 12 & 119.6 & 72.8 & 57 & 12 & 117.0 & 69.0 & 92 \\
\hline 13 & 114.4 & 67.7 & 202 & 13 & 110.0 & 67.9 & 153 \\
\hline 14 & 108.5 & 67.8 & 29 & 14 & 110.2 & 65.9 & 27 \\
\hline \multicolumn{8}{|c|}{ Age $20-29$} \\
\hline 10 & - & - & - & 10 & 188.0 & 120.0 & 1 \\
\hline 11 & 136.9 & 88.5 & 12 & 11 & 128.8 & 81.8 & 39 \\
\hline 12 & 131.5 & 80.2 & 97 & 12 & 123.2 & 77.7 & 131 \\
\hline 13 & 128.6 & 79.7 & 115 & 13 & 122.5 & 78.1 & 92 \\
\hline 14 & 111.8 & 70.7 & & 14 & 116.5 & 72.0 & 4 \\
\hline 10 & - & & \multicolumn{2}{|c|}{ Age 30-39 } & 138 & & \\
\hline 11 & 146.1 & 98.7 & $\overline{11}$ & $\begin{array}{l}10 \\
11\end{array}$ & $\begin{array}{l}1.38 .6 \\
130.3\end{array}$ & $\begin{array}{l}89.4 \\
00^{3}\end{array}$ & 13 \\
\hline 12 & 140.6 & 88.8 & 54 & 12 & 134.8 & $\begin{array}{l}90.3 \\
86.5\end{array}$ & $\begin{array}{l}45 \\
75\end{array}$ \\
\hline 13 & 133.5 & 85.9 & 47 & 13 & 132.5 & 80.9 & 36 \\
\hline 14 & 184.0 & 110.0 & 2 & 14 & 111.3 & 68.7 & 3 \\
\hline & & & \multicolumn{2}{|c|}{ Age $40-49$} & & & \\
\hline 10 & 139.0 & 81.0 & 2 & 10 & 159.3 & 98.3 & 11 \\
\hline 11 & 148.8 & 96.5 & 13 & 11 & 160.6 & 95.5 & 56 \\
\hline 12 & 142.1 & 93.7 & 63 & 12 & 146.2 & 90.8 & 75 \\
\hline 13 & 140.3 & 90.4 & 54 & 13 & 144.7 & 89.9 & 26 \\
\hline 14 & 142.0 & 88.0 & 2 & Age $50-59$ & 140.3 & 78.0 & 4 \\
\hline 10 & 一 & - & - & 10 & 172.5 & 95.5 & 13 \\
\hline 11 & 181.3 & 100.7 & 6 & 11 & 171.1 & 96.5 & 20 \\
\hline 12 & 150.7 & 92.5 & 31 & 12 & 156.1 & 91.7 & 37 \\
\hline 13 & 144.6 & 87.3 & 26 & 13 & 158.4 & 91.1 & 16 \\
\hline 14 & m & 一 & \multirow{2}{*}{\multicolumn{2}{|c|}{$60+$}} & - & - & - \\
\hline 10 & 1740 & 840 & $1^{A-1}$ & & & & \\
\hline 11 & 170.9 & 98.3 & $\frac{1}{7}$ & $\begin{array}{l}10 \\
11\end{array}$ & $\begin{array}{l}190.8 \\
186.1\end{array}$ & $\begin{array}{l}95.0 \\
946\end{array}$ & \\
\hline 12 & 186.1 & 90.5 & 8 & 12 & 171.0 & 88.5 & 22 \\
\hline 13 & 151.6 & 84.0 & 17 & 13 & 172.5 & 85.3 & 18 \\
\hline 14 & 210.0 & 110.0 & 2 & 14 & 153.0 & 90.0 & 2 \\
\hline
\end{tabular}

of both races tend to be alike in this respect (increasing heaviness with age). Thus it seems that the body build and its correlate, arm girth (for which similar data were obtained), is a definite factor influencing blood pressure, but probably less important than was previously thought. Boe's ${ }^{1}$ exhaustive work also suggests this conclusion.

Since women of reproductive age of both races showed relatively lower mean systolic pressures than males, an attempt was made to determine the effect of parity on blood pressure. Humerfelt and Wedervang ${ }^{3}$ found that the average 
blood pressure was inversely related to the number of children borne by the women they studied (the group was at the end of the reproductive cycle). Their finding could not be reproduced in this study, as seen in Table IV.

Table IV. Relationship of Parity to Blood Pressure Within Age GroupNegro Females, Nassau, 1958

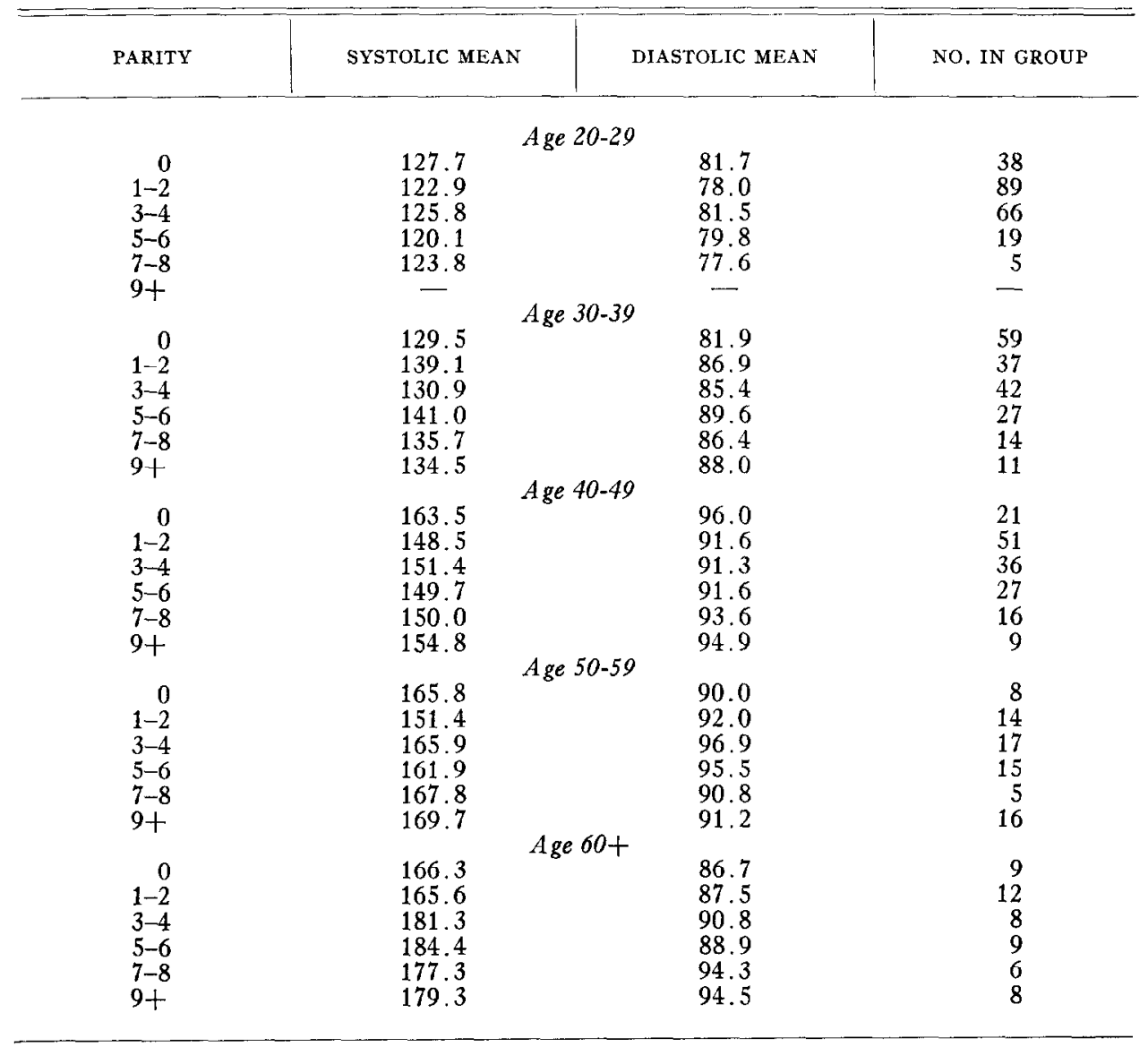

\section{SUMMARY}

Results of a study of blood pressure levels in Negro and white residents of Nassau, Bahamas, have been presented. Persons for study were selected by means of probability sample design. The purpose of the study was to describe as accurately as possible the differing patterns of blood pressure with regard to race, age, and sex. The site was selected because of the opportunity to study the two races in a somewhat different environment and perhaps mode of life than previously reported by others. Also, the water supply of the area is known to be high in salt.

The following facts were disclosed:

1. A definite racial difference is seen. The pattern of progression of blood pressure with age is almost linear in the Negro. The white race, however, shows a flattening or "plateau" effect from the time adult ages are reached until middle 
life, when mean blood pressure again tends to rise. 'This is seen in the means of both systolic and diastolic pressure, but most noticeably in regard to the systolic.

2. Sex differences are shown. Women of both races have lower mean systolic pressures during the reproductive years than men of their race. Negro men have slightly but consistently higher mean diastolic pressures than women almost throughout life.

3. Comparison with population studies elsewhere leads to the conclusion that Bahamian Negroes resemble Negroes elsewhere in the Western Hemisphere and Bahamian white persons resemble white people in other geographic locations in regard to blood pressure. A particularly provocative comparison is that of Bahamian Negroes with Negroes in St. Kitts (Leeward Islands), ${ }^{8}$ since blood pressure patterns appear similar, despite high salt intake in the Bahamas and low salt intake in St. Kitts.

We are indebted to Dr. S. W. Hoobler, Dr. Marvin Moser, and Dr. H. J. Dodge for their extensive assistance with the planning of the study.

This work was greatly facilitated by the interest and cooperation of Dr. E. H. Murcott, Chief Medical Officer of the Colonial Medical Service in Nassau, and the staff of the Princess Margaret Hospital.

\section{REFERENCES}

1. Boe, J., Humerfelt, S., and Wedervang, F.: The Blood Pressure in a Population, Acta med. scandinav., supp. 321, pp. 1-336, 1957.

2. Comstock, G. W.: An Epidemiological Study of Blood Pressure Levels in a Biracial Community in the Southern United States, Am. J. Hyg. 65:271, 1957.

3. Humerfelt, S., and Wedervang, F.: Further Analysis of the Bergen Blood Pressure Survey, Acta med. scandinav. 159:489, 1957.

4. Lohr, E. W., and Love, S. K.: The Industrial Utility of Public Water Supplies in the U. S., 1952: Geological Survey Water Supply Papers 1299, 1300, Washington, D. C., 1954, U. S. Government Printing Office.

5. Miall, W. E., and Oldham, P. D.: A Study of Arterial Blood Pressure and Its Inheritance in a Sample of the General Population, Clin. Sc. 14:459, 1955.

6. Moser, M., Morgan, R., Hale, M., Hoobler, S. W., Remington, R. D., Dodge, H. J., and Macaulay, A. I.: Epidemiology of Hypertension With Particular Reference to the Bahamas. I. Preliminary Report of Blood Pressures and Review of Possible Etiologic Factors, Am. J. Cardiol., 4:727, 1959.

7. Pickering, G. W.: High Blood Pressure. New York, 1955, Grune \& Stratton, Inc.

8. Schneckloth, R. E. and Corcoran, A. C.: Personal communication.

\section{APPENDIX}

With the aid of the IBM 704 electronic computer, extensive statistical computations have been completed for each of the 14 basic measurements in the study. These 14 measurements are:

1. Systolic blood pressure, first reading.

2. Diastolic blood pressure; phase IV, first reading.

3. Diastolic blood pressure; phase $V$, first reading.

4. Pulse pressure (systolic minus diastolic phase V), first reading.

5. Pulse rate, first reading.

6-10. (Same as $1-5$, but second reading.)

11. Height.

12. Weight.

13. Height-weight index. (Height/cube root of weight).

14. Arm girth.

Means, variances, and standard errors based on the probability sample design were computed for each of the 14 measurements by age, sex, and race subgroup.

To facilitate further mathematical studies of the structure of blood pressure distributions, descriptive means, variances, standard deviations, coefficients of skewness, and coefficients of kurtosis were computed for the 14 measurements by age, sex, and race.

Copies of these tabulations are available from the authors by request. 